\title{
Deciphering the effects of kosmotrope and chaotrope salts during aqueous two phase extraction (ATPE) of polyphenolic compounds and glycoalkaloids from the leaves of a nutraceutical plant, Solanum retroflexum, with the aid of UPLC-QTOF-MS
}

\author{
Tebogo Mokgehle1, Ntakadzeni Madala ${ }^{2 *}$, Wilson Gitari ${ }^{3}$ and Nikita Tavengwa ${ }^{{ }^{*}}$
}

\begin{abstract}
Solanum plants (Solanaceae) are renowned source of nutraceuticals and have widely been explored for their phytochemical constituents. This work investigated the effects of kosmotropic and chaotropic salts on the number of phytochemicals extracted from the leaves of a nutraceutical plant, Solanum retroflexum, and analyzed on the ultraperformance liquid chromatography hyphenated to a quadrupole time of flight mass spectrometer (UPLC-QTOF-MS) detector. Here, a total of 20 different compounds were putatively characterized. The majority of the identified compounds were polyphenols and glycoalkaloids. Another compound, caffeoyl malate was identified for the first time in this plant. Glycoalkaloids such as solanelagnin, solamargine, solasonine, $\beta$-solanine (I) and $\beta$-solanine (II) were found to be extracted by almost all the salts used herein. Kosmotrope salts, overall, were more efficient in extracting polar compounds with 4 more polyphenolic compounds extracted compared to the chaotropes. Chaotropes were generally more selective for the extraction of less polar compounds (glycoalkaloids) with 3 more extracted than the kosmotropes. The chaotrope and the kosmotrope that extracted the most metabolites were $\mathrm{NaCl}$ and $\mathrm{Na}_{2} \mathrm{SO}_{4}$, respectively, with 12 metabolites extracted for each salt. This work demonstrated that a comprehensive metabolome of S. retroflexum, more than what was previously reported on the same plant, can be achieved by application of kosmotropes and chaotropes as extractants with the aid of the Aqueous Two Phase Extraction approach. The best-performing salts, $\mathrm{Na}_{2} \mathrm{SO}_{4}$ or $\mathrm{NaCl}$, could potentially be applied on a commercial scale, to meet the ever-growing demand of the studied metabolites. The Aqueous Two Phase Extraction technique was found to be efficient in simultaneous extraction of multiple metabolites which can be applied in metabolomics.
\end{abstract}

Keywords: Aqueous Two Phase Extraction, Chaotropes, Kosmotropes, Solanum retroflexum, Extraction

*Correspondence: ntaka.madala@univen.ac.za; nikita.tavengwa@univen.ac.za ${ }^{1}$ Department of Chemistry, School of Mathematical and Natural Sciences, University of Venda, Private Bag X5050, Thohoyandou 0950, South Africa

2 Department of Biochemistry, School of Mathematical and Natural Sciences, University of Venda, Private Bag X5050, Thohoyandou 0950, South Africa

Full list of author information is available at the end of the article

\section{Introduction}

Solanum plants (Solanaceae) have been widely explored for their phytochemical constituents. These bioactive compounds have been isolated from various parts of plants such as leaves, fruits and roots [1-3]. The presence of various phytochemicals in Solanum plants has allowed for their use in medicine, food and dietary supplements 
[4]. The type of phytochemical compounds found in Solanum plants vary with species, plant part and the extraction method.

In view of the rich diversity of Solanum phytochemicals, these substances have recently become of great interest owing to their versatile applications as basic raw materials for indigenous pharmaceuticals. These phytochemicals are a rich bio-resource of drugs for traditional systems of medicine, modern medicines, nutraceuticals, pharmaceutical intermediates and chemical entities for synthetic drugs [5, 6]. Examples of phytochemicals include polyphenolic flavonoid compounds which are widely distributed in plants and have been reported to exert multiple biological effects, including antioxidant, free radical scavenging abilities, anti-inflammatory and anti-carcinogenic characteristics [3, 7]. Glycoalkaloids, which are common alkaloids within the Solanaceae family have been reported to play a protective role in species such as S. tuberosum, S. melongena and S. lycopersium [8-10]. The defensive role of glycoalkaloids include redox imbalance, disruption of biological membranes, disturbed metabolism, inhibition of cholinesterase, reproductive toxicity and disturbed development [11].

Patel et al. [12] reported on phytochemicals such as carbohydrates, saponins, tannins, alkaloids and triterpenoids in S. dubium roots. Piana et al. [1] reported on the presence of phenolic alkaloids and flavonoids compounds from ethanol extracts in S. corymbiflorum leaves. Upreti et al. [13] studied the phytochemical constituents of $S$. xanthocarpum fruits, obtained through methanolic extraction, and found that it contained alkaloids and glycosides. Daji et al. [14] investigated the phytochemical profile of $S$. retroflexum leaves using methanolic extracts and found a rage of cinnamic acids, polyphenols and alkaloids.

In light of the wide range of bioactive roles that phytochemicals display, extraction of these essential compounds is all the more worthwhile. Extraction of phytoconstituents from plants is dependent on a variety of factors, among which includes the use of chaotropic and kosmotropic salts. Chaotropes are salts that disrupt hydrophobic interactions of plant derived compounds in water, hence allowing for dissolution of non-polar compounds in water. They are also weakly hydrated compounds and generally consist of large singly charged ions. On the contrary, kosmotropes do not interfere with hydrophobic interactions and are strongly hydrated as a result of their structural design, which consists of small multiply charged ions.

Aqueous two-phase system (ATPE) is a liquid-liquid partitioning method where one layer is composed of a bottom salt-saturated aqueous layer and an upper organic extraction solvent for separation, purification and enrichment of metabolites [15]. Aqueous two-phase extraction has been recognized as a versatile technique for the downstream processing of biomolecules [16, 17]. The major advantages of ATPE are high capacity, biocompatible environment, low interfacial tension of phases, high yields and low process time [16, 18]. Additionally, this technique uses salts that allow for partitioning of ethanol (green solvent) from water, where the ethanol layer is enriched with metabolites. This extraction method is renowned for its ability to extract, separate, purify and enrich proteins, viruses and membranes, resulting in decent yields $[18,19]$. Recently, researchers have turned their attention to an improved version of ATPE, saltingout assisted liquid-liquid extraction (SALLE) technique, which facilitates enhanced extraction of metabolites from complex matrices. This method uses solvents such as ethanol $(\mathrm{EtOH})$ or acetonitrile $(\mathrm{MeCN})$, as extraction solvents because water-solubility is minimized when salts are added to samples and extraction media [20,21]. The SALLE procedure has been widely applied for extraction of compounds from various matrices because of its simplicity and effectiveness [21-26].

To the best of our knowledge, information on extraction of phytochemicals using chaotropes and kosmotropes is scarce. Hence, the aim of this work was to determine if ATPE using the salting-out technique was efficient in obtaining a comprehensive metabolome of $S$. retroflexum. If the study were to be successful, it would be the first of its kind. The efficiency of the saltingout technique was determined based on the number of metabolites that would have been extracted from the aqueous solution into the extractant phase using a group of kosmotropic and chaotropic salts. Analysis and characterization of the extracted metabolites was performed on the UPLC-QTOF-MS.

\section{Experimental}

\section{Chemicals and reagents}

All salts; $\mathrm{KNO}_{3}$ (analytical grade $\geq 99 \%$ purity), $\mathrm{Na}_{2} \mathrm{SO}_{4}$ (analytical grade $\geq 99 \%$ purity), $\mathrm{BaCl}_{2} \cdot 2 \mathrm{H}_{2} \mathrm{O}$ (ACS reagent $\geq 99 \%$ purity), $\mathrm{KBr}$ (anhydrous $\geq 99 \%$ purity), $\mathrm{MgCl}_{2} \cdot 6 \mathrm{H}_{2} \mathrm{O}$ (anhydrous $\geq 99 \%$ purity), $\mathrm{Na}_{2} \mathrm{HPO}_{4}$ (anhydrous $\geq 99 \%$ purity), $\mathrm{NaCl}$ (anhydrous $\geq 99 \%$ purity), $\mathrm{NaH}_{2} \mathrm{PO}_{4} \cdot 2 \mathrm{H}_{2} \mathrm{O}$ (anhydrous $\geq 99 \%$ purity), $\left(\mathrm{NH}_{4}\right)_{2} \mathrm{SO}_{4}$ (anhydrous $\geq 99 \%$ purity), $\quad \mathrm{Na}_{2} \mathrm{CO}_{3} \quad$ (anhydrous $\geq 99 \%$ purity), $\mathrm{KCl}$ (anhydrous $\geq 99 \%$ purity), $\mathrm{AgNO}_{3}$ (Analytical reagent $\geq 99 \%$ purity) and Ethanol $(99 \% \mathrm{CP})$ were purchased from Associated Chemical Enterprises (Johannesburg, South Africa) and Sigma-Aldrich (Johannesburg, South Africa). Ultra-pure water $(0.005 \mu \mathrm{S}, 18 \mathrm{~m} \Omega)$ was used for the preparation of the salt solutions. Chromatographic separation was conducted using an Acquity UHPLC (Ultra high performance liquid chromatography) 
instrument. The UPLC was connected to a Synapt G1 qTOF-MS detector (Waters Corporation, MA, USA). The solvents used for the chromatographic runs were acetonitrile and formic acid, which were purchased from Romil Pure Chemistry (Cambridge, UK).

\section{Sample collection, preparation and ATPE}

The leaves of $S$. retroflexum were obtained from a street vendor within the Thulamela District in Thohoyandou, South Africa. The plants were air dried until a constant weight was obtained, and the leaves were ground into a fine powder with a blender at $2000 \mathrm{rpm}$ and stored in glass containers. The containers were covered in paper bags to prevent light penetration. The powdered leaves $(2.00 \mathrm{~g})$ were placed in $50 \mathrm{~mL}$ centrifuge tubes. Thereafter, saturated salt concentrations of $30 \%(\mathrm{w} / \mathrm{v})$ involving kosmotropes $\left(\mathrm{BaCl}_{2} \cdot 2 \mathrm{H}_{2} \mathrm{O}, \mathrm{Na}_{2} \mathrm{SO}_{4}, \mathrm{Na}_{2} \mathrm{CO}_{3},\left(\mathrm{NH}_{4}\right)_{2} \mathrm{SO}_{4}\right.$, $\mathrm{Na}_{2} \mathrm{HPO}_{4}$ and $\left.\mathrm{MgCl}_{2} \cdot 6 \mathrm{H}_{2} \mathrm{O}\right)$ and chaotropes $\left(\mathrm{AgNO}_{3}\right.$, $\mathrm{KBr}, \mathrm{KCl}, \mathrm{KNO}_{3}, \mathrm{NaH}_{2} \mathrm{PO}_{4} \cdot 2 \mathrm{H}_{2} \mathrm{O}$ and $\mathrm{NaCl}$ which were prepared by weighing $15 \mathrm{~g}$ of salt in $50 \mathrm{~mL}$ of water, were added to the powdered leaves. The mixture was then shaken on the dragon shaker at $70 \mathrm{rpm}$ for $12 \mathrm{~h}$ at $25{ }^{\circ} \mathrm{C}$ for the extraction of the metabolites. The ethanol extraction solvent $(20 \mathrm{~mL})$ was then added to the mixture for enrichment of the salt extracted metabolites that were initially in the aqueous phase, resulting in ATPE. The ATPE extractions were done in duplicates. The bottom layer contained the saturated salt while the top layer contained $99 \%$ ethanol extracting solvent. The metabolites contained in the extracts were then analysed on a UPLC-QTOF-MS.

\section{Analysis on the UPLC-QTOF-MS}

Chromatographic separation was conducted on an Acquity HSS T3 C18 column $(150 \mathrm{~mm} \times 2.1 \mathrm{~mm}$ with particle size of $1.7 \mu \mathrm{m}$ ) using a mobile phase which consisted of formic acid (0.1\%) in deionised water (solvent A) and acetonitrile with $0.1 \%$ formic acid (solvent $\mathrm{B}$ ) at a column temperature of $40{ }^{\circ} \mathrm{C}$. Chromatographic separation was achieved using a $20 \mathrm{~min}$ gradient elution method consisting of the following settings: the initial conditions were $98 \%$ solvent $\mathrm{A}$ at a flow rate of $0.4 \mathrm{~mL} \mathrm{~min}{ }^{-1}$. The conditions were kept constant for $1 \mathrm{~min}$. Conditions were changed to $98 \%$ solvent $\mathrm{A}$ at $1 \mathrm{~min}$, sharply reduced to $5 \%$ solvent $\mathrm{A}$ at $6 \mathrm{~min}$, held for $2 \mathrm{~min}$, and then changed to $98 \%$ solvent $\mathrm{A}$ and maintained at $8 \mathrm{~min}$ for the next $2 \mathrm{~min}$. Elution was monitored using a photodiode-array detector (PDA) collecting 20 spectra per second between the 200 and $500 \mathrm{~nm}$ range.

For mass spectrometry, the acquisition parameters discussed by Ramabulana et al. [27] were followed. Briefly, MS data were acquired using positive and negative electron spray ionization (ESI) modes. The MS was configured to scan the range of $100-1000 \mathrm{Da}$ with a scan time of $0.2 \mathrm{~s}$. After a series of optimization, the following settings were found to be optimal: capillary voltage of $2.5 \mathrm{kV}$, sample cone potential of $30 \mathrm{~V}$, source temperature of $120{ }^{\circ} \mathrm{C}$, desolvation temperature of $450{ }^{\circ} \mathrm{C}$, cone gas flow of $50 \mathrm{~L} \mathrm{~h}^{-1}$, desolvation gas flow of $550 \mathrm{~L} \mathrm{~h}^{-1}$, and multichannel plate detector potential of $1600 \mathrm{~V}$. In order to achieve efficient fragmentation to aid during identification, the mass spectrometry data were collected using a collision energy ramp of 10-30 eV. Structural elucidation was done using KNapSAck online metabolite database.

\section{Results and discussion}

LC-MS analysis of metabolites obtained from leaves of $S$. retroflexum using ethanol extracts from the ATPE system LC-MS analysis of chlorogenic acids and related esters

Generally, approximately 15 polyphenolic compounds and 5 glycoalkaloids were identified, as presented in Fig. 1a, b. Peaks at $m / z 353$ which indicated caffeoylquinic acids (CQAs) when kosmotropes and chaotropes were used are shown in Fig. 1a and b. Madala et al. [28], Deshpande et al. [29] and Mhlongo et al. [30] have reported CQA at $m / z 353$. Chlorogenic acids are a family of esters that result from the esterification reaction of quinic acid (QA) and cinnamic acid (CA) derivatives comprised of either caffeic or coumaroyl or ferulic acid [31]. Kosmotrope salts such as $\mathrm{MgCl}_{2} \cdot 6 \mathrm{H}_{2} \mathrm{O}, \mathrm{Na}_{2} \mathrm{HPO}_{4}$ and $\mathrm{Na}_{2} \mathrm{SO}_{4}$ extracted CQAs as identified in the chromatograms (Fig. 1a and b). As for the chaotropes, CQAs were also identified for $\mathrm{NaCl}, \mathrm{NaH}_{2} \mathrm{PO}_{4} \cdot 2 \mathrm{H}_{2} \mathrm{O}$ and $\mathrm{KCl}$ (Fig. 1b). Multiple peaks at $m / z 353$ with retention times of 2.60, 3.51 and $3.53 \mathrm{~min}$ in Fig. 1a and b were observed and indicated isomers of CQA. Daji et al. [14] reported a similar observation when methanol extracts were screened on the UPLC-qTOF-MS. A precursor ion at $\mathrm{m} / z 295$ with a retention time of 4.32 min was observed for all the kosmotropes and chaotropes except for $\mathrm{AgNO}_{3}, \mathrm{KNO}_{3}$ and $\mathrm{Na}_{2} \mathrm{CO}_{3}$. Interestingly, the precursor ion at $m / z 295$ and 4.32 min was not reported by Daji et al. [14] in the methanol extracts they analyzed on the UPLC-qTOF-MS, probably indicating that this was a unique compound.

\section{LC-MS analysis of flavonoids}

recursor ions at $m / z 609$ and $m / z 593$ appeared at $5.10 \mathrm{~min}$ and $5.51 \mathrm{~min}$, respectively and were observed for most of the kosmotropic salts and chaotropic salts (Fig. 1a and b). Similarly, Daji et al. [14], Ramabulana et al. [27] and Pinela et al. [32] reported on precursor ions at $m / z 609$ and $m / z 593$ as flavonoids. 


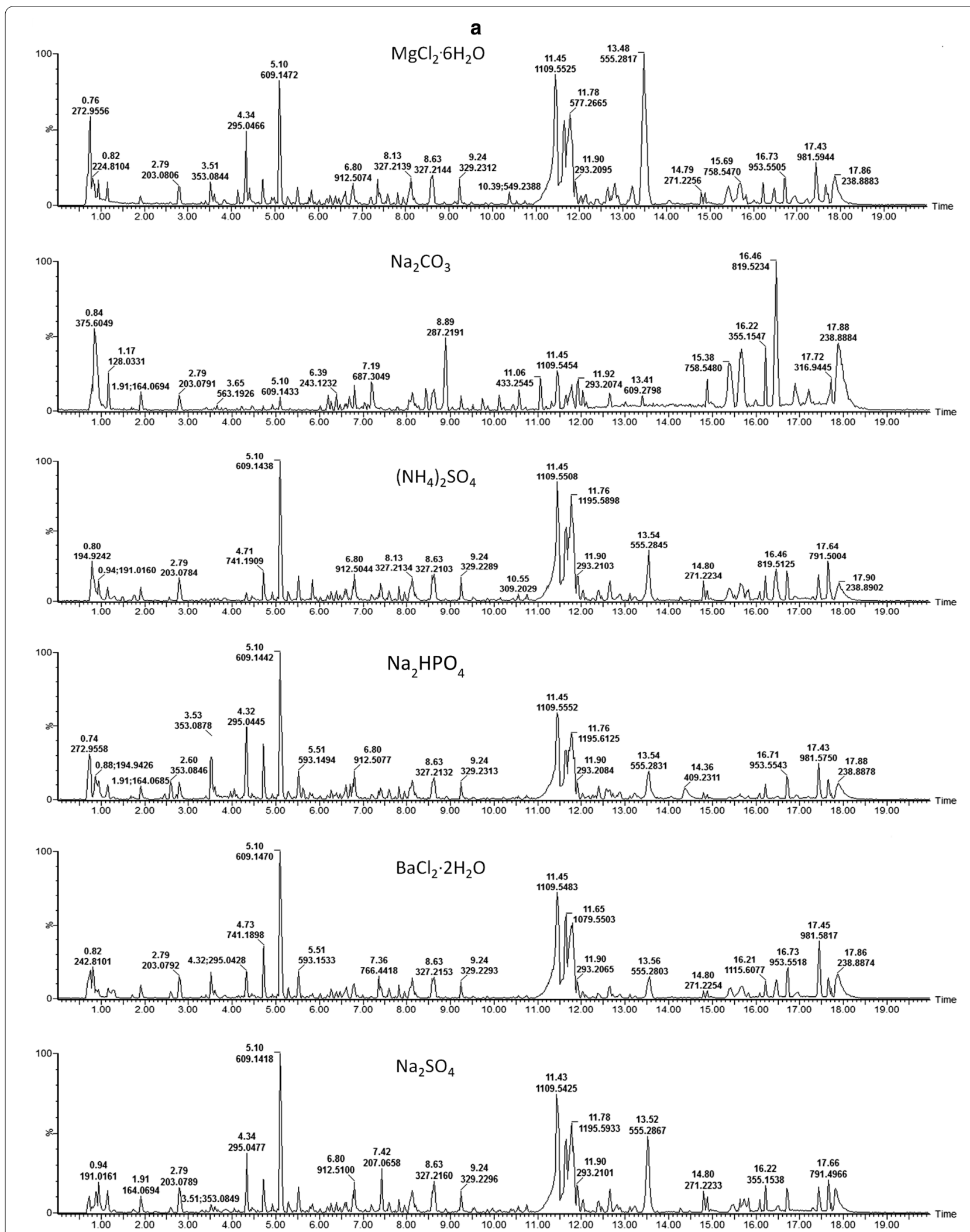

Fig. 1 Base peak single-ion UHPLC-qTOF-MS chromatograms of polyphenolic metabolites extracted using ethanol via ATPE from leaves of S. retroflexum using (a) kosmotropes and (b) chaotropes 
Mokgehle et al. App Biol Chem $\quad$ (2021)64:28

Page 5 of 15
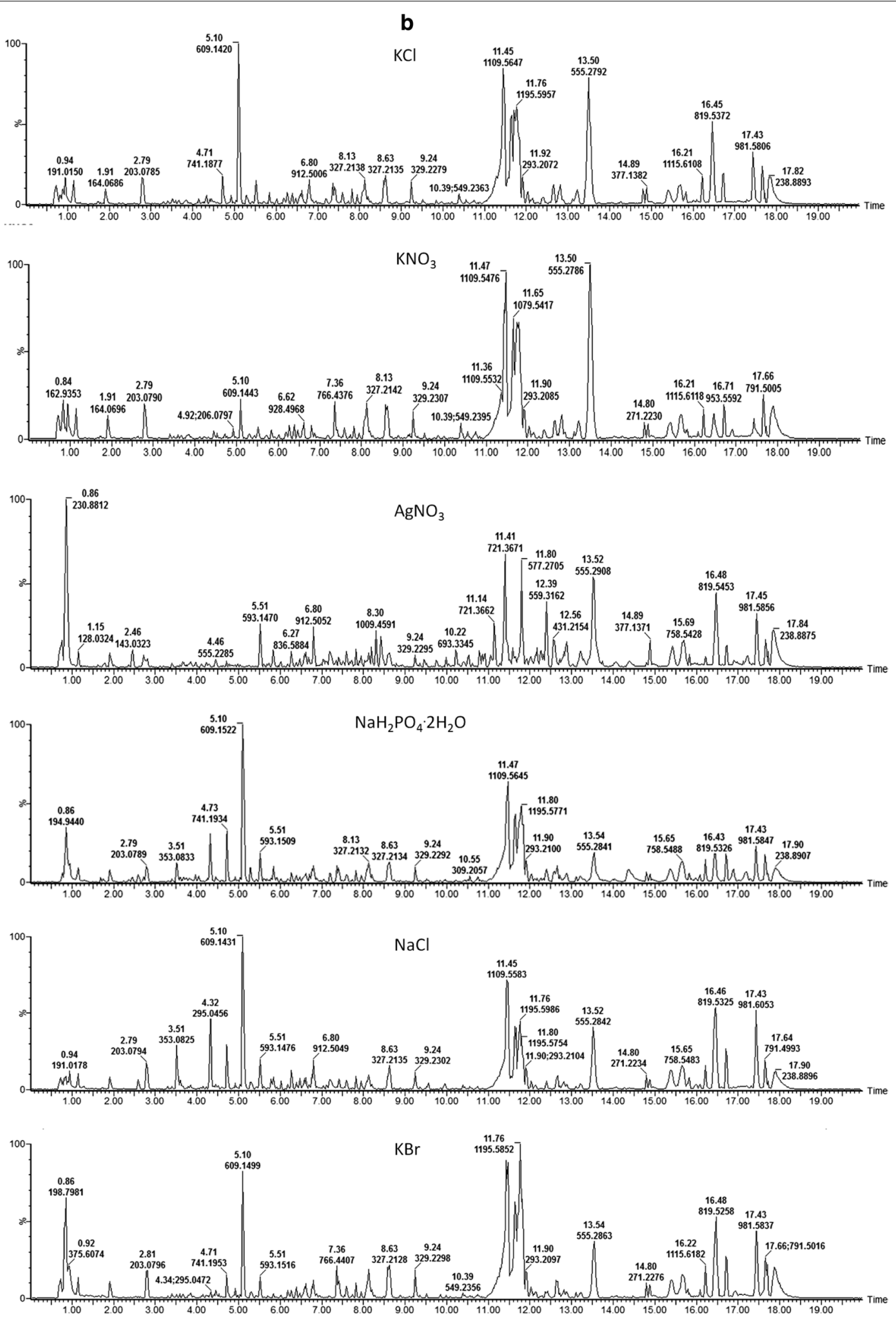

Fig. 1 continued 


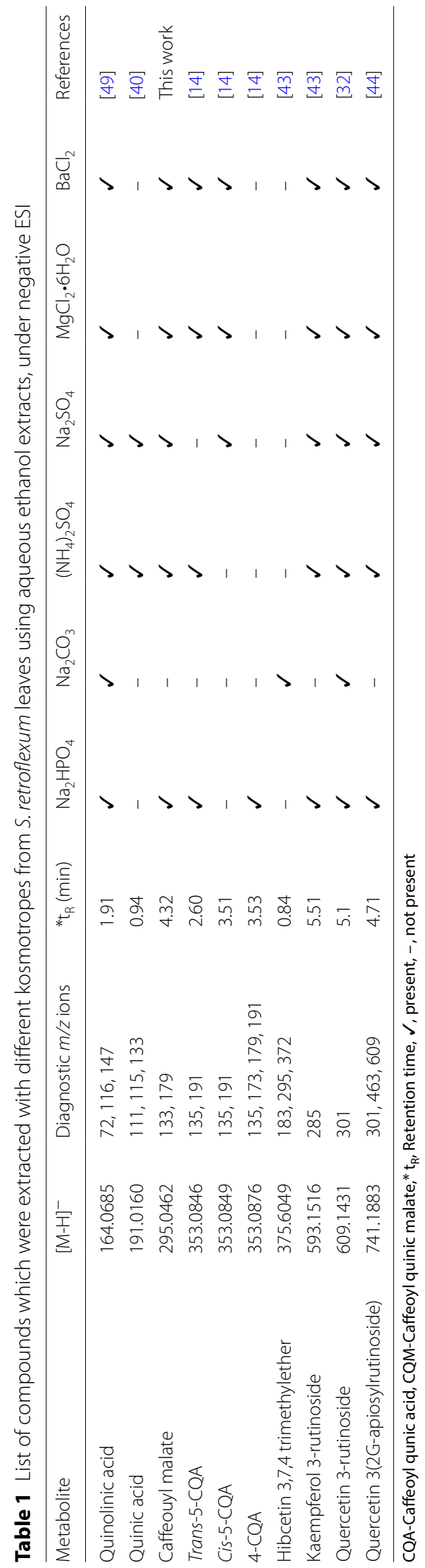




\section{LC-MS analysis of glycoalkaloids}

Two glycoalkaloid isomers at $m / z 868$ were obtained for most of the chaotropes and kosmotropes. Two other glycoalkaloid isomers at $\mathrm{m} / z 722$ were observed for the majority of chaotropes and kosmotropes. The occurrence of metabolites at $m / z 868$ and $m / z 722$ has been reported as glycoalkaloids in a variety of Solanum plants, examples include; S. tuberosum [33], S. chacoense [34] and S. retroflexum [14].

\section{Mass spectra of metabolites obtained from leaves of $\mathrm{S}$. retroflexum \\ Mass spectra of chlorogenic acids and related esters}

As discussed previously, a variety of peaks at $\mathrm{m} / z 353$ with unique retention times were obtained which indicated the presence of isomeric compounds. The isomers were distinguished using the tandem MS/MS approach which generated fragmentation patterns from the precursor ion $(\mathrm{m} / z$ 353). The isomers at $2.59,3.51,3.59$ and $4.10 \mathrm{~min}$ had diagnostic $\mathrm{m} / \mathrm{z}$ ions of $(135,191)$, (135, $191),(135,173,179,191)$ and $(135,179,191)$, respectively. Hence, the isomers that eluted at 2.59, 3.51, 3.59 and $4.10 \mathrm{~min}$ were identified as 5-CQA, 4-CQA and 3-CQA, respectively, indicating that positional (monoacylated) isomers of CQA were extracted by the majority of kosmotropes and chaotropes. Abu-Reidah et al. [35] and Piana et al. [1] also reported on positional isomers of CQA acids in leaves of L. intricatum and leaves of $S$. corimbiflorum, respectively. The detected fragments $\mathrm{m} / \mathrm{z}$ 191 (quinic acid-H), $m / z 179$ (caffeic acid-H), $m / z 173$ (quinic acid- $\mathrm{H}_{2} \mathrm{O}$ ) and $m / z 135$ (caffeic acid- $\mathrm{CO}_{2}$ ) were reported by Che et al. [36], Deshpande et al. [29] and Mhlongo et al. [30]. Additionally, 5-CQA was obtained at 2.59 and $3.51 \mathrm{~min}$, indicating the possibility of geometric isomers. Daji et al. [14] also reported on the geometric isomers of mono-acylated CQAs using a reverse phase column and observed that trans mono-acylated CQAs eluted before cis mono-acylated CQAs. Thus, the 5-CQA isomers that eluted at 2.59 and $3.51 \mathrm{~min}$ were trans-5-CQA and cis-5-CQA, respectively. The extracted CQAs are useful pharmacological compounds and were reported for anti-inflammatory activity [37-39]. The CQAs obtained using the various kosmotropes and chaotropes studied, are also summarized in Tables 1 and 2.

A compound identified at $m / z 295$ and retention time of 4.32 min was extracted by most of the chaotropes and kosmotropes. The fragmentation pattern of compound yielded fragments at $m / z 179$ and $m / z 133$. The fragment at $m / z 179$ was identified as caffeic acid-H while $m / z 133$ had a chemical formula of $\mathrm{C}_{4} \mathrm{H}_{5} \mathrm{O}_{5}$ and through the KNapSAck metabolite database, was identified as malic acid-H. The process of structural elucidation was done by obtaining the chemical formula, which was observed to be $\mathrm{C}_{13} \mathrm{H}_{11} \mathrm{O}_{8}$ at $\mathrm{m} / z$ 295, and thereafter identifying the metabolite using the KNapSAck metabolite database, which was determined to be caffeoyl malate as shown in Fig. 2. This highlighted that caffeoyl malate was synthesized from the esterification reaction of caffeic acid and malic acid in a similar way to which Solanum plants would synthesize CQA from CA and QA [14, 40, 41]. It is worth noting that caffeoyl malate was not detected in any other Solanum species to date, though similar metabolites such as feuralic malate and coumaric malate have been reported in Fabaceae plants, $P$. vulgaris, [27]. Therefore, it is the first time caffeoyl malate has been identified in species of Solanum.

\section{Mass spectra of flavonoids}

Precursor ions at $m / z 609$ and $m / z 593$ were detected on the UPLC-QTOF-MS, which appeared at $5.10 \mathrm{~min}$ and $5.51 \mathrm{~min}$ on the chromatogram for most of the chaotropes and kosmotropes. The daughter ions at $\mathrm{m} / \mathrm{z}$ 609 and $m / z 593$ were $m / z 301$ and $m / z 515$, respectively. Hence, the compounds at $m / z 609$ and $m / z 593$ were identified as quercetin-3-rutinoside and kaempferol-3-rutinoside, respectively. Quercetin-3-rutinoside and kaempferol-3-rutinoside were reported in S. retroflexum [14], P. vulgaris [27] and in V. Schreb [42]. A compound at $m / z 741$ was found for most of the chaotropes and kosmotropes at $4.71 \mathrm{~min}$ (Fig. 1a and b). The daughter ions of the compound at $m / z 741$ were $m / z 609$ and $m / z 300$ which corresponded to quercetin 3 -rutinoside- $\mathrm{H}$ and quercetin- $\mathrm{H}^{*}$ are shown in Fig. 3. The chemical formula of the compound at $m / z 741$ was determined to be $\mathrm{C}_{32} \mathrm{H}_{37} \mathrm{O}_{20}$. Structural elucidation of the compound $(m / z 741)$ using the KNapSAck metabolite database indicated that the compound was quercetin 3-(2G-apiosylrutinoside). This compound was reported in C. pallidiculale [43] and S. glaucophyllum [44]. Additionally, Litvinov [45] reported on the importance of glycosylated sugar moieties, at position 3 and 7 on the quercetin and kaempferol core moieties, in the bioavailability of flavonoid glycosides in humans. Additionally, flavonoids were reported to form complexes with bacterial cell walls, inhibiting microbial growth [14, 46-48]. Hence, glycosylated flavonoids are essential compounds in food additives and pharmacological applications. The identity of the flavonoids, the diagnostic $\mathrm{m} / \mathrm{z}$ ions and retention times are summarized in Tables 1 and 2 for the kosmotropes and chaotropes, respectively. 
Table 2 List of compounds which were extracted with different chaotropes from S. retroflexum leaves using aqueous ethanol extracts, under negative ESI

\begin{tabular}{|c|c|c|c|c|c|c|c|c|c|c|}
\hline Metabolite & {$[\mathrm{M}-\mathrm{H}]^{-}$} & Diagnostic $m / z$ ions & ${ }^{*} t_{R}(\min )$ & $\mathrm{NaCl}$ & $\mathrm{Na} . \mathrm{X}$ & $\mathrm{AgNO}_{3}$ & $\mathrm{KBr}$ & $\mathrm{KCl}$ & $\mathrm{KNO}_{3}$ & References \\
\hline Quinolic acid & 164.0685 & $72,116,147$ & 1.91 & $\checkmark$ & $\checkmark$ & $\checkmark$ & $\checkmark$ & $\checkmark$ & $\begin{array}{l}\checkmark \\
\checkmark\end{array}$ & [49] \\
\hline Quinic acid & 191.0160 & $111,115,133$ & 0.94 & $\checkmark$ & - & - & - & $\checkmark$ & $\checkmark$ & [40] \\
\hline CQM & 295.0462 & 133,179 & 4.32 & $\checkmark$ & $\checkmark$ & - & $\checkmark$ & $\checkmark$ & - & This work \\
\hline Trans-5-CQA & 353.0846 & 135,191 & 2.60 & $\checkmark$ & $\checkmark$ & - & - & - & - & [14] \\
\hline Cis-5-CQA & 353.0849 & 135,191 & 3.51 & $\checkmark$ & $\checkmark$ & - & - & $\checkmark$ & - & [14] \\
\hline 4-CQA & 353.0876 & $135,173,179,191$ & 3.53 & - & - & - & - & - & - & [14] \\
\hline Hibcetin. 3,7,4 trimethylether & 375.6049 & $183,295,372$ & 0.84 & - & - & - & - & - & $\checkmark$ & [43] \\
\hline Kaempferol-3 rutinoside & 593.1516 & 285 & 5.51 & $\checkmark$ & $\checkmark$ & $\checkmark$ & $\checkmark$ & $\checkmark$ & $\checkmark$ & [43] \\
\hline Quercetin-3 rutinoside & 609.1431 & 301 & 5.1 & $\checkmark$ & $\checkmark$ & - & $\checkmark$ & $\begin{array}{l}\checkmark \\
\checkmark\end{array}$ & $\checkmark$ & {$[32]$} \\
\hline Quercetin.3(2G-apiosylrutinoside) & 741.1883 & $301,463,609$ & 4.71 & $\checkmark$ & $\checkmark$ & - & $\checkmark$ & $\checkmark$ & - & [44] \\
\hline
\end{tabular}

CQA, Caffeoyl qunic acid, CQM, Caffeoyl quinic malate, $\mathrm{Na} \cdot \mathrm{X}-\mathrm{NaH}_{2} \mathrm{PO}_{4} \cdot 2 \mathrm{H}_{2} \mathrm{O}$, present, - , not present, ${ }^{*} \mathrm{t}_{\mathrm{R}}$, Retention time

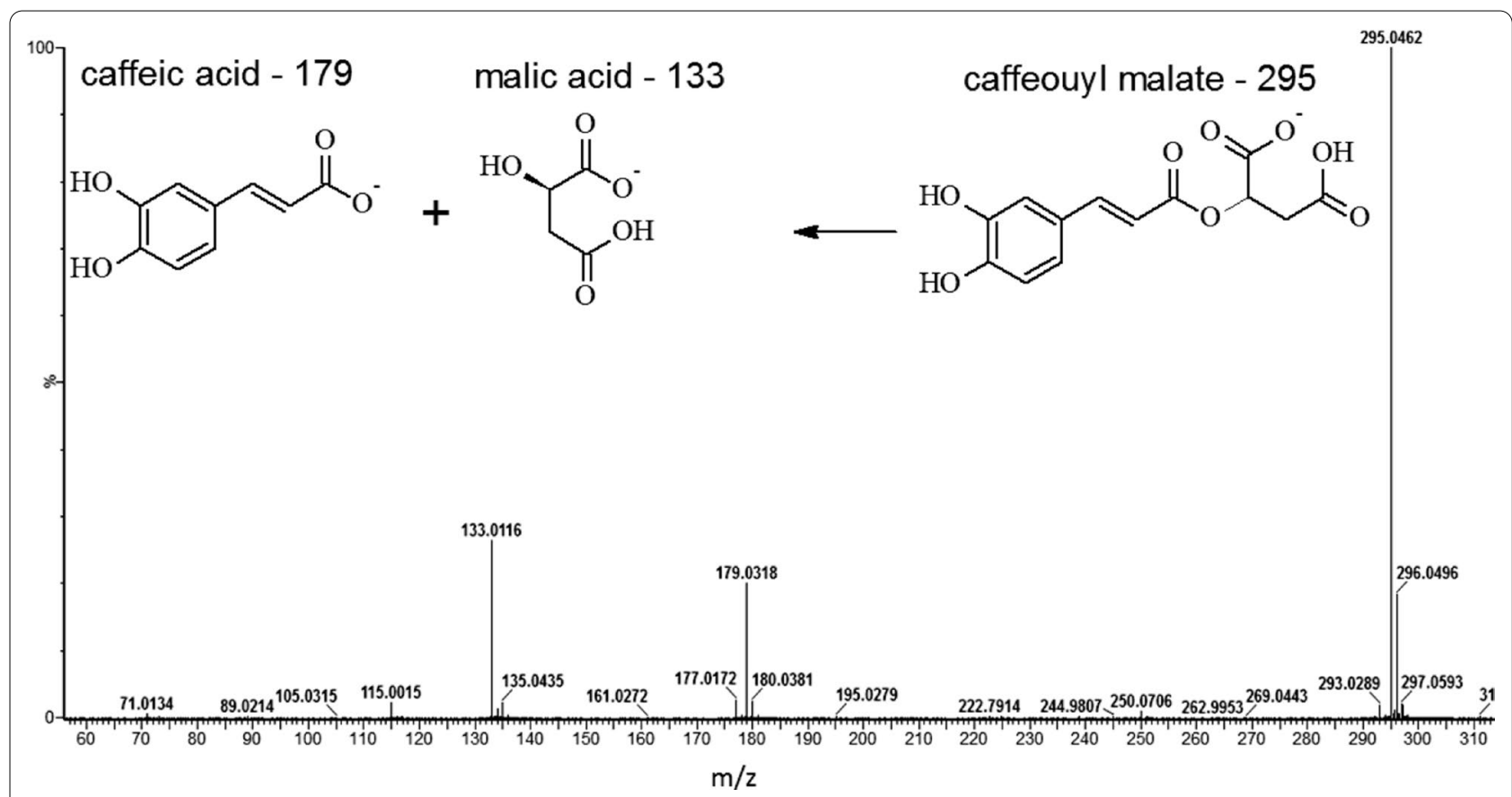

Fig. 2 Fragmentation pattern of caffeoyl malate using ESI negative ionization mode

\section{Mass spectra of alkaloid derivatives}

Two isomeric compounds at $m / z 868$ at retention times of 6.59 and $6.81 \mathrm{~min}$ were extracted for all kosmotropes and chaotropes, with the exception of $\mathrm{MgCl}_{2} \cdot 6 \mathrm{H}_{2} \mathrm{O}$. The fragmentation patterns of both isomers were very similar with each isomer consisting of daughter ions at $m / z 414$ and 722 as shown in Additional file 1: Figs. S1 and S2. The chemical formulae of the two isomers at $m / z 868$ were found to be identical $\left(\mathrm{C}_{45} \mathrm{H}_{74} \mathrm{NO}_{15}\right)$ indicating that both compounds contained the same aglycone unit with the same sugar side chain of uniquely positionally arranged monosaccharides. The occurrence of the same aglycone unit is substantiated by the presence of the fragment $\mathrm{m} / z$ 414 for both isomers in Additional file 1: Figs. S1 and S2, which was identified as solasodine $\left(\mathrm{C}_{27} \mathrm{H}_{43} \mathrm{NO}_{2}\right)$. From the KNapSAcK metabolite database, only two metabolites at $m / z 868$ matched the formula $\mathrm{C}_{45} \mathrm{H}_{74} \mathrm{NO}_{15}$ and were identified as solanelagnin and solamargine. Both solanelagnin and solamargine contained the same aglycone unit (solasodine) and the same chacotriose sugar 


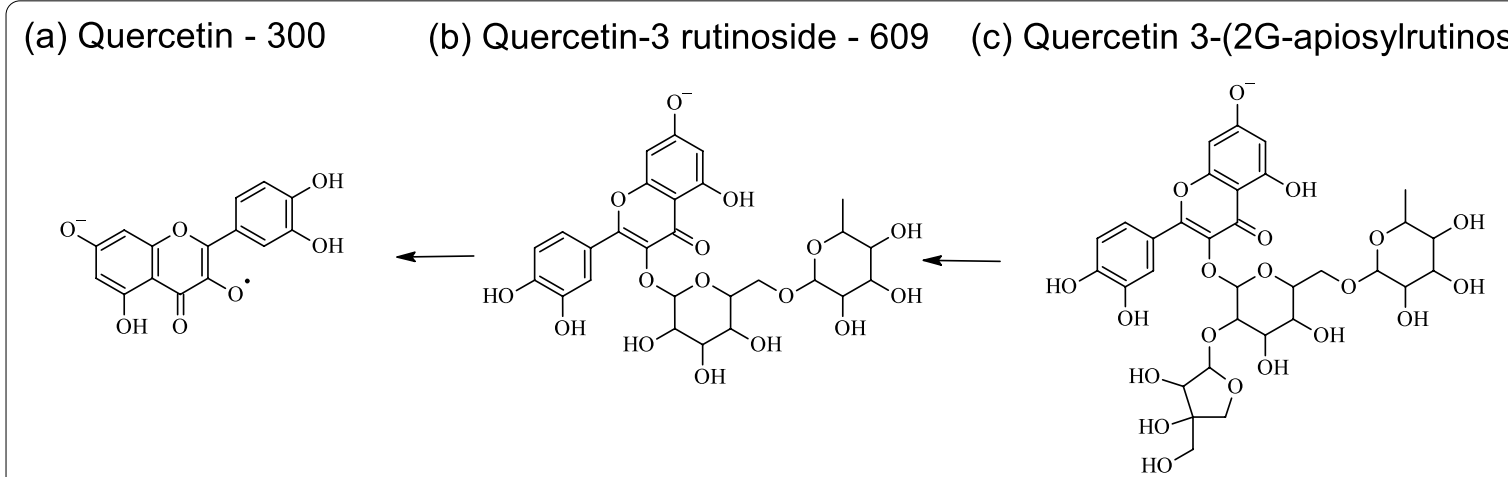

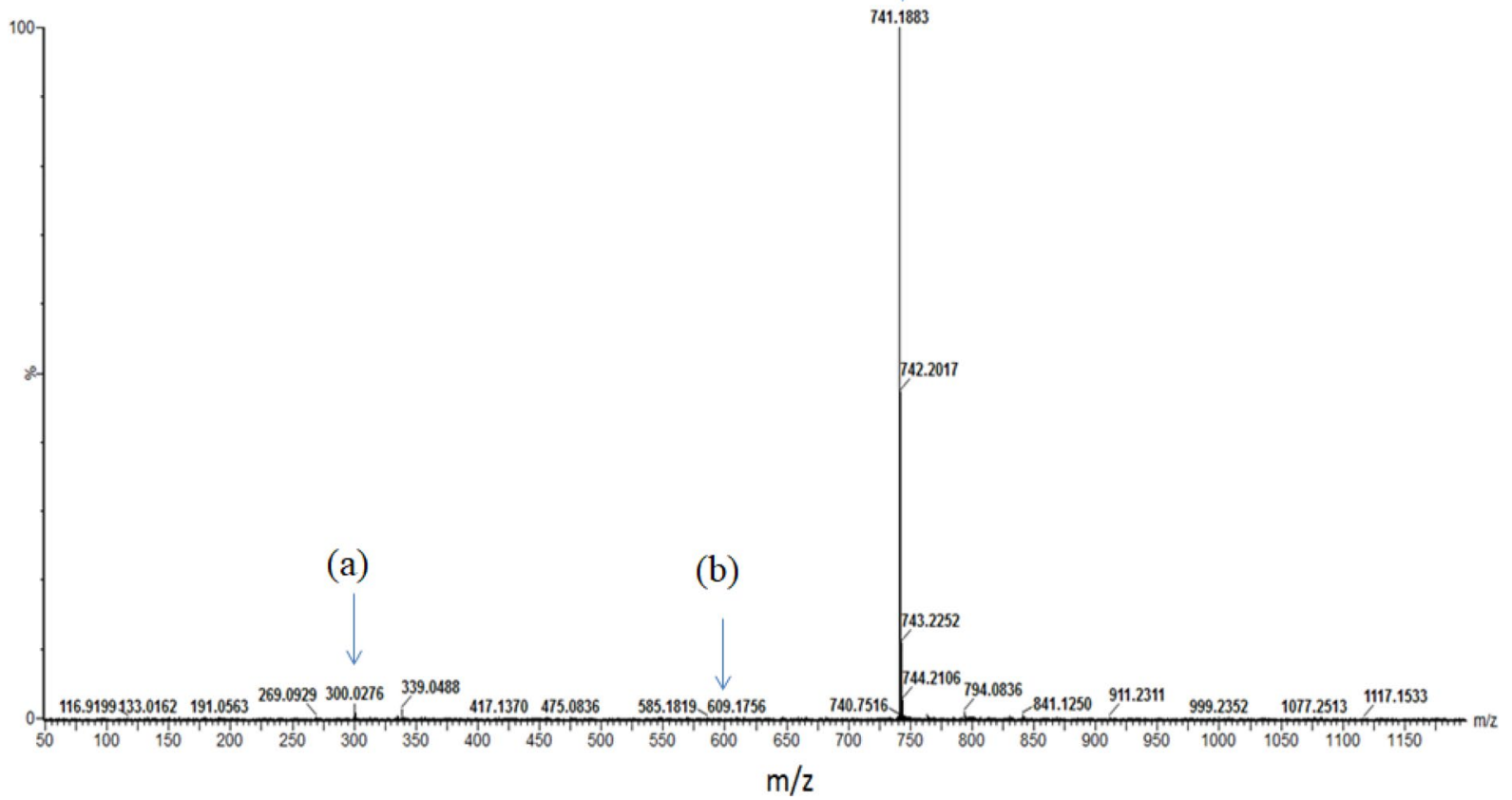

Fig. 3 Mass spectrum showing the fragmentation pattern and scheme of quercetin 3-(2G-apiosylrutinoside) to quercetin

side chain, which was composed of glucose and two rhamnose sugars. Chacotriose was glycosylated to solasodine through glucose, in both isomers. The only difference between the two isomers was the positional glycosylation of the rhamnose sugars to glucose. In solanelagnin, the rhamnose sugars were glycosylated at position 3 and 4 of glucose while in solamargine, glycosylation occurred at position 2 and 4 (Additional file 1: Figs. S1 and S2). Solanelagnin, due to the close proximity of the rhamnose sugars in comparison to solamargine, was observed to be the more polar, and hence eluted earlier at $6.59 \mathrm{~min}$ while solamargine followed at $6.81 \mathrm{~min}$ (Additional file 1: Fig. S3). Solamargine has been identified in other Solanum species such as in leaves of S. incanum, S. nigrum and S. retroflexum while solanelagnin was reported in S. elaeagnifolium [14, 50, 51]. Solamargine is highly toxic, intake at low doses can cause vomiting and diarrhea while high dosage intake can lead to death [14, 52]. Solanelagnin was reported to exhibit hepatoprotection against paracetamol induced liver injury in mice [53]. The toxicity of glycoalkaloids is due to its aglycone unit which is toxic and non-polar [27, 33].

Two other isomeric compounds at $m / z 722$ with retention times of 6.87 and 7.38 min were extracted for most kosmotropes and chaotropes. The fragmentation patterns of both isomers were similar with both isomers exhibiting daughter ions at $m / z 397$ and 559 as shown in Additional file 1: Fig. S4a and b, similarly to what was observed for the isomers at $m / z$ 868. The chemical formulae of the two isomers at $m / z 772$ were determined to be identical 


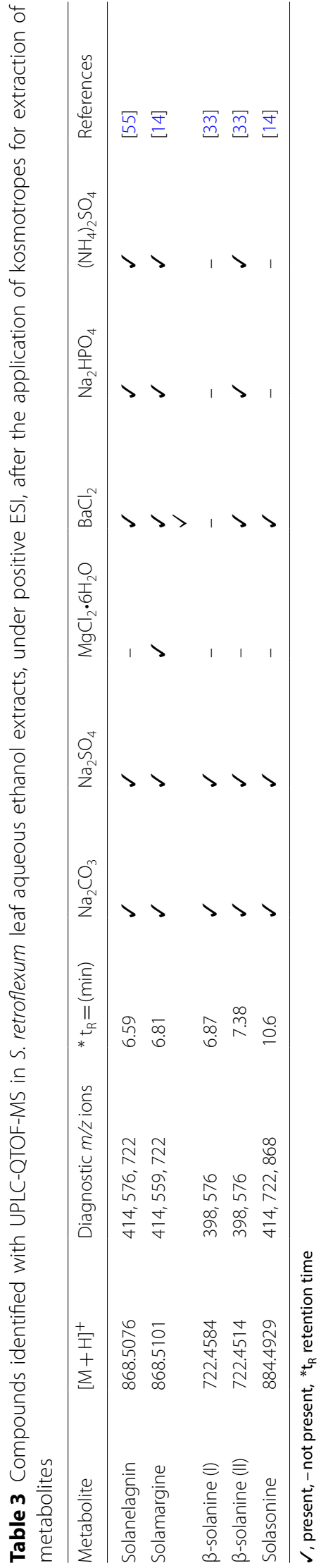


$\left(\mathrm{C}_{39} \mathrm{H}_{64} \mathrm{NO}_{11}\right)$ indicating that both compounds contained the same aglycone unit with the same sugar side chain of uniquely positionally arranged monosaccharides. The occurrence of the same aglycone unit was due to the presence of the fragment at $\mathrm{m} / \mathrm{z} 397$ for both isomers in Additional file 1: Fig. S4a and b, which was identified as solanidine $\left(\mathrm{C}_{27} \mathrm{H}_{43} \mathrm{NO}\right)$. Structural elucidation of the isomers at $m / z 722\left(\mathrm{C}_{39} \mathrm{H}_{64} \mathrm{NO}_{11}\right)$ using KNapSAcK metabolite database indicated that the compounds were isomers of $\beta$-solanine. $\beta$-solanine (I) and $\beta$-solanine (II) had the same aglycone unit, solanidine, and the same carbohydrate sugar side chain, solabiose, which both contained epimers glucose and galactose. Solabiose was glycosylated to solanidine through galactose in both isomers. In $\beta$-solanine (I) glycosylation of glucose to galactose occurred at position 4 while in $\beta$-solanine (II) glycosylation of glucose occurred at position 3 . $\beta$-solanine (I) was shown to be glycosylated at position 4 which made glucose and galactose appear in close proximity to each other than $\beta$-solanine (II). Therefore, $\beta$-solanine (I) had a greater dipole moment than $\beta$-solanine (II), and hence eluted earlier at $6.87 \mathrm{~min}$ while solamargine followed at 7.38 min (Additional file 1: Fig. S5). Tata et al. [33] and Jia et al. [54] reported on the presence of $\beta$-solanine in sprouts of $S$. tuberosum. $\beta$-solanine was also reported by Filho et al. [41] to be less toxic than solamargine.

Kosmotropic salts such as $\mathrm{Na}_{2} \mathrm{CO}_{3}, \mathrm{Na}_{2} \mathrm{SO}_{4}$ and $\mathrm{BaCl}_{2}$ were observed to extract solasonine while the same metabolite was not extracted for any of the chaotropes (Tables 3 and 4). This suggested the solasonine extraction is probably favored by the presence of multiply charged ions. The chaotrope salts were observed to extract a number of glycoalkaloids (Table 4). This indicated that generally chaotropes tend to have a greater affinity than kosmotropes for extraction compounds of lower polarity such as glycoalkaloids as compared to polyphenols. Identification of glycoalkaloids in this work further emphasized the prevalence of these toxic compounds among Solanum species that play a defensive role against microorganisms and competing plants [8-10]. The glycoalkaloids obtained from the kosmotropes and chaotropes are shown in Tables 3 and 4.

Figure 4 is a general reaction mechanism illustrating the reaction of chaotropes and kosmotropes with a plant metabolite in the aqueous phase of the ATPE system. A general observation from the extraction of polyphenols and glycoalkaloids was that kosmotropes were more efficient in extracting polar compounds such as polyphenols while the chaotropes were better off in extraction of less polar compounds such as glycoalkaloids. The mechanistics of this observation can be explained by the manner in which kosmotropes and chaotropes interact with water in the aqueous phase based on the salting-out effect.
Salting-out is an effective pre-concentration method which has been studied for the extraction of Vitamin D3 in milk samples [26] partitioning of biomolecules [56] and determination of 5-nitroimidazolesin in fish [21]. Salting-out is dependent on the nature of the salt involved. Kosmotropes have been studied to form strong hydrogen bonds with water as opposed to chaotropes [57-60]. In the aqueous phase, S. retroflexum metabolites interacted with the water molecules through mainly, hydrogen bonds followed by weaker interactions such as electrostatic forces, dipole-dipole forces and van der wall forces. Introduction of salts in the aqueous phase resulted in the salting-out effect, whereby interactions between the water and the metabolites were disturbed. As a result, the miscibility of the phytochemicals for the water solvent was reduced resulting in precipitation of metabolites from the aqueous phase. The extent of precipitation was dependent on the nature of the salt (kosmotrope or chaotrope) and the polarity of the precipitated compounds. The ethanol extraction solvent that was introduced, removed the precipitated phytochemicals from the aqueous phase. Similarly, as shown in Fig. 4, the kosmotrope $\left(\mathrm{Na}_{2} \mathrm{SO}_{4}\right)$ formed strong hydrogen bonds with the water molecules surrounding the metabolite (chlorogenic acid) as opposed to chaotropes. This led to the precipitation of the resultant metabolite from the aqueous phase, of which was eventually removed by the ethanol extractant solution. Hence, generally, a greater number of polyphenolic metabolites in this study were observed for kosmotropes as opposed to chaotropes (Tables 1, 2, 3 and 4).

For a chaotrope such as $\mathrm{AgNO}_{3}$, which had the least amount of polyphenols extracted, while extracting all the glycoalkaloids present, can be explained based on saltingout effect. Additionally, silver has a destructive effect, as it has been reported to be persistent, bioaccumulative, and toxic to both aquatic species and plants. For instance, silver ions were shown to inhibit seed germination, biomass accumulation, and root and shoot growth in Arabidopsis [61], B. nigra [62], Lemna [63], P. radiatus [64] and Lupinus termis L. [65]. Similarly, the silver ions could have reacted directly with the metabolites (polyphenols in particular), as a result changing the polarity of the metabolite, subsequently reducing its precipitation from the aqueous phase. Hence, only two polyphenolic metabolites were observed for $\mathrm{AgNO}_{3}$ as seen in Table 2.

Most ATPE techniques have been limited to a particular number of compounds, for instance Nainegali et al. [66] obtained four bioactive compounds from Garcinia indica. Other studies on ATPE were limited to a particular kind of bioactive compound. For example, Zhang et al. [67] used sodium citrate/sodium tartate ATPE system for extraction of glycyrrhizic acid from licorice while Santos et al. [68] extracted betanin from a 
Table 4 Compounds identified with UPLC-QTOF-MS in S. retroflexum leaf aqueous ethanol extracts, under positive ESI, after the application of chaotropes for extraction of metabolites

\begin{tabular}{lllllllllll}
\hline Metabolite & {$[\mathrm{M}+\mathrm{H}]^{+}$} & Diagnostic $\mathrm{m} / \mathrm{z}$ ions & ${ }^{*} \mathrm{t}_{\mathrm{R}}=(\mathrm{min})$ & $\mathrm{KCl}$ & $\mathrm{AgNO}_{3}$ & $\mathrm{KNO}_{3}$ & $\mathrm{KBr}$ & $\mathrm{NaCl}$ & $\mathrm{NaH}_{2} \mathrm{PO}_{4} \cdot 2 \mathrm{H}_{2} \mathrm{O}$ & $\mathrm{References}$ \\
\hline Solanelagnin & 868.5076 & $414,576,722$ & 6.59 & $\checkmark$ & $\checkmark$ & $\checkmark$ & $\checkmark$ & $\checkmark$ & $\checkmark$ & {$[55]$} \\
Solamargine & 868.5101 & $414,559,722$ & 6.81 & $\checkmark$ & $\checkmark$ & $\checkmark$ & $\checkmark$ & $\checkmark$ & $\checkmark$ & {$[14]$} \\
$\beta$-solanine (I) & 722.4584 & 398,576 & 6.87 & $\checkmark$ & $\checkmark$ & $\checkmark$ & $\checkmark$ & $\checkmark$ & $\checkmark$ & {$[33]$} \\
$\beta$-solanine (II) & 722.4514 & 398,576 & 7.39 & $\checkmark$ & $\checkmark$ & $\checkmark$ & $\checkmark$ & $\checkmark$ & $\checkmark$ & {$[33]$} \\
Solasonine & 884.4929 & $414,722,868$ & 10.6 & - & - & - & - & - & - & {$[14]$} \\
\hline
\end{tabular}

$\checkmark$, present, -, not present, ${ }^{*} t_{R}$, retention time

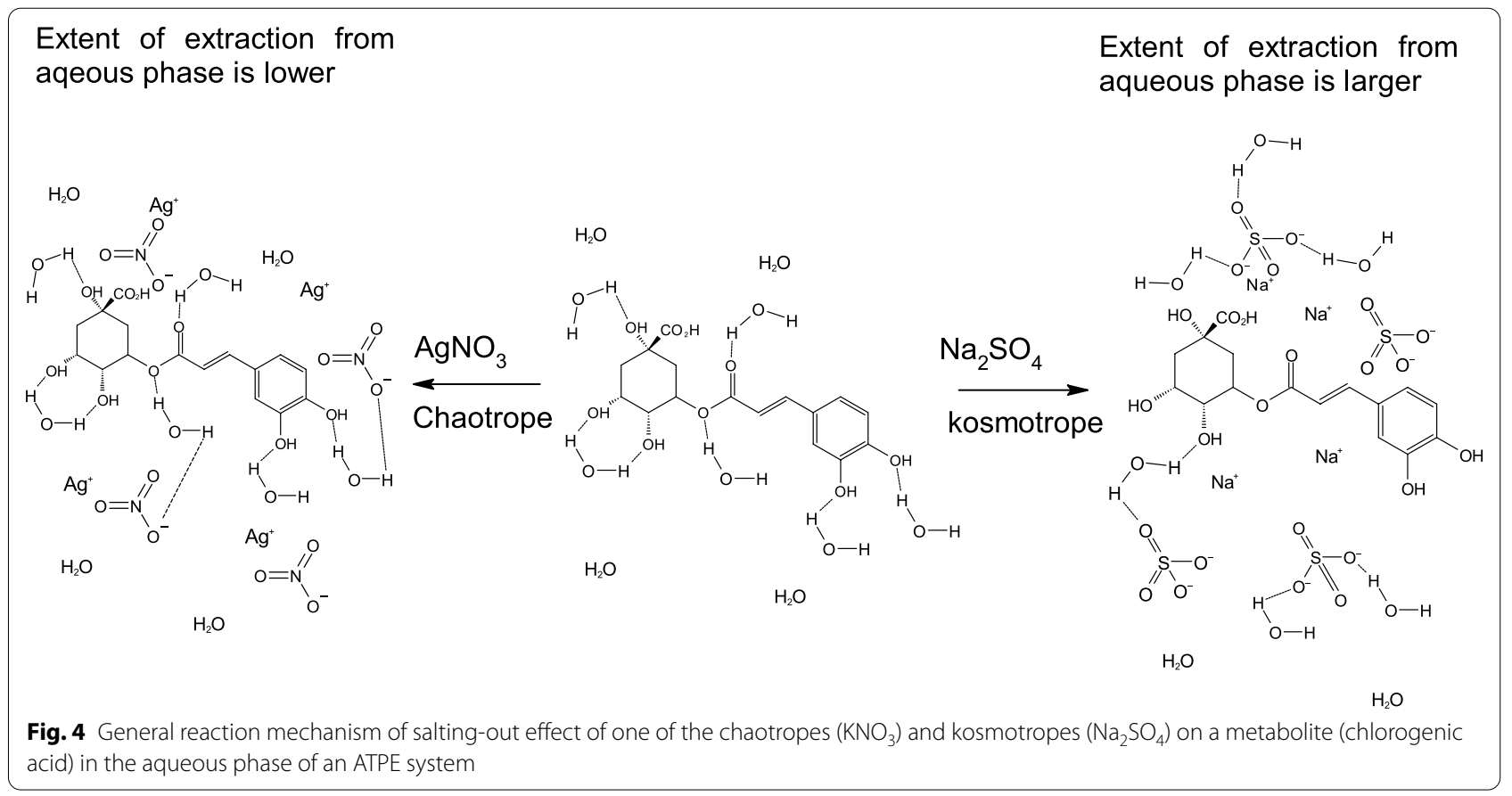

THF/sodium salt system. This study, however, exploited the versatility of the salts involved in ATPE, where the chaotrope and the kosmotrope that extracted the most metabolites was $\mathrm{NaCl}$ and $\mathrm{Na}_{2} \mathrm{SO}_{4}$, with 12 metabolites extracted for each salt which included polyphenols and glycoalkaloids from leaves of $S$. retroflexum. The chaotrope $\left(\mathrm{Na}_{2} \mathrm{SO}_{4}\right)$ aided in the extraction of 7 polyphenolic compounds (Table 1) and 5 glycoalkaloids (Table 3) while the kosmotrope $(\mathrm{NaCl})$ facilitated the extraction of 8 polyphenolic compounds (Table 1) and 4 glycoalkaloids (Table 3 ). This indicated that a range of bioactive compounds can be simultaneously extracted using a single salt, making the extraction process less tedious. The robustness of single salts in ATPE can be further exploited with an intension to be applied in advanced scientific disciplines such as metabolomics.

\section{Conclusion}

The ATPE technique based on the salting-out method was shown to be an efficient approach for simultaneous extraction of multiple metabolites from S. retroflexum, more than what was previously reported on the same plant. Approximately, 20 different compounds were putatively identified. From the polyphenols, caffeoyl malate was obtained at $m / z 295$, and to the best of our knowledge, it has not been reported in other species of Solanum plants. Five glycoalkaloids were identified in this study which included two pairs of isomeric compounds at $m / z 868$ solanelagnin and solamargine, at $m / z 722 \beta$-solanine (I) and $\beta$-solanine (II) and at $\mathrm{m} / z 884$ solasonine. Herein, kosmotropes were generally more efficient in the extraction of polar compounds, 38 polyphenols overall (Table 1) compared to 
the 34 identified for the chaotropes (Table 2). On the other hand chaotropes were better extractants of less polar compounds such as glycoalkaloids with an overall amount of 24 being identified (Table 4) in comparison to 21 obtained for the komostropes (Table 3). The chaotrope and the kosmotrope that extracted the most metabolites was $\mathrm{NaCl}$ and $\mathrm{Na}_{2} \mathrm{SO}_{4}$, with 12 metabolites extracted for each salt. The chaotrope $\left(\mathrm{Na}_{2} \mathrm{SO}_{4}\right)$ aided in the extraction of 7 polyphenolic compounds (Table 1) and 5 glycoalkaloids (Table 3 ) while the kosmotrope $(\mathrm{NaCl})$ facilitated the extraction of 8 polyphenolic compounds (Table 1) and 4 glycoalkaloids (Table 3). Some of the metabolites obtained in this work were not found in literature reporting on the extraction phytochemicals from S. retroflexum leaves. This indicated that komotropes and chaotropes were better extractants of metabolites that could potentially have nutraceutical applications. Though the scope of this study was focused on qualitative determination of compounds extracted from S. retroflexum using ATPE, more work needs to be directed at quantification and optimization of the metabolites obtained, particularly glycoalkaloids owing to their potential pharmacological applications. For instance, studies can be directed at examining the biological properties of isomeric glycoalkaloid compounds. Additionally, studies involving hepatoprotection by isomeric glycoalkaloids obtained from S. retroflexum can also be conducted. The chaotropes and kosmotropes applied in this study, which had extracted most of the nutraceuticals, can potentially be applied on a commercial scale, to meet the ever-growing demand of the studied metabolites.

\section{Supplementary Information}

The online version contains supplementary material available at https://doi. org/10.1186/s13765-021-00603-8.

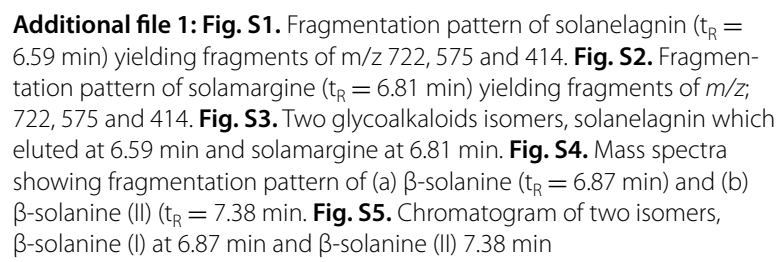
$6.59 \mathrm{~min}$ ) yielding fragments of $\mathrm{m} / \mathrm{z} 722,575$ and 414. Fig. S2. Fragmentation pattern of solamargine $\left(t_{R}=6.81 \mathrm{~min}\right.$ ) yielding fragments of $\mathrm{m} / \mathrm{z}$; 722, 575 and 414. Fig. S3. Two glycoalkaloids isomers, solanelagnin which eluted at $6.59 \mathrm{~min}$ and solamargine at $6.81 \mathrm{~min}$. Fig. S4. Mass spectra showing fragmentation pattern of (a) $\beta$-solanine ( $t_{R}=6.87 \mathrm{~min}$ ) and (b) $\beta$-solanine (II) ( $t_{R}=7.38$ min. Fig. S5. Chromatogram of two isomers, $\beta$-solanine (I) at $6.87 \mathrm{~min}$ and $\beta$-solanine (II) $7.38 \mathrm{~min}$

\section{Acknowledgements}

The authors would also like to express their gratitude to the Council for Scientific and Industrial Research studies for their technical support. The University of Venda is also thanked for financial support.

\section{Authors' contributions}

TM, NT and NEM conceived the study, TM and NEM conducted the experiments and data analyses. NT, NM and WG supervised the project. WG helped to draft the manuscript. All authors read and approved the final manuscript.

\section{Funding}

The national research Foundation (NRF) of South Africa and the University of Venda are thanked for financial support.

Availability of data and materials

Raw data will be provided upon request.

\section{Declarations}

Competing interests

None.

\section{Author details}

${ }^{1}$ Department of Chemistry, School of Mathematical and Natural Sciences, University of Venda, Private Bag X5050, Thohoyandou 0950, South Africa.

${ }^{2}$ Department of Biochemistry, School of Mathematical and Natural Sciences, University of Venda, Private Bag X5050, Thohoyandou 0950, South Africa.

${ }^{3}$ Department of Ecology and Resource Management, School of Environmental Sciences, University of Venda, Private Bag X5050, Thohoyandou 0950, South Africa.

Received: 17 September 2020 Accepted: 26 February 2021

Published online: 08 March 2021

\section{References}

1. Piana M, Camponogra C, Boligon A (2016) Topical anti-inflammatory activity of Solanum corymbiflorum leaves. J Ethnopharmacol 179:16-21

2. Yousaf Z, Wang Y, Baydoun E (2013) Phytochemistry and pharmacological studies on Solanum torvum. J Appl Pharm Sci 3:152-160

3. Kumar S, Kumar M (2009) Antioxidant and free radical scavenging activities of edible weeds. Afr J Food Agric Nutr Dev 9:1174-1190

4. Neascu M, Vaughn N, Raikos V (2015) Phytochemical profile of commercially available food plant powders their potential role in healthier food reformulations. Food Chem 179:159-169

5. Saranraj P, Sivasakti S, Deepa M (2016) Phytochemistry of pharamcologically important medicinal plants-a review. Int J Curr Res Chem Pharm Sci 3:56-66

6. Yuan H, Ma Q, Piao G (2016) The traditional medicine and modern medicine from natural products. Molecules 559:1-18

7. Olugbami J, Gbadegesin M, Odunola O (2015) In vitro free radical scavenging and antioxidant properties of ethanol extract of Terminalia glaucescens. Pharmacogn Res 7:49-56

8. Montero-Vargas JM, Casarrubias-Castillo K, Martínez-Gallardo N, OrdazOrtiz JJ, Délano-Friera JP, Winkler R (2018) Modulation of steroidal glycoalkaloid biosynthesis in tomato (Solanum lycopersicum) by jasmonic acid. Plant Sci. 277:155-165

9. Fogelman E, Oren-Shamir M, Hirschberg J, Mandolino G, Parisi B, Ovadia R (2019) Nutritional value of potato (Solanum tuberosum) in hot climates: anthocyanins, carotenoids, and steroidal glycoalkaloids. Planta 249:1143-1145

10. Fekry MI, Ezzat SM, Salama MM, Alshehri OY, Al-Abd AM (2019) Bioactive glycoalkaloides isolated from Solanum melongena fruit peels with potential anticancer properties against hepatocellular carcinoma cells. Sci Rep 9:1-11

11. Chowanski S, Adamski Z, Marciniak P, Rosinski G, Buyukguzel E, Buyukguzel K, Falabella P, Scrano L, Ventrella E, Lelario L, Bufo SA (2016) A review of the bioinsecticidal activity of solanaceae alkaloids. Toxins 8:1-60

12. Patel VBR, Kotak N, Pandya P (2018) Phytochemical and pharmacognostical investigation on solanum dubium fresen. Root Int J Pharm Biol Sci Arch 6:2349-2678

13. Upreti R, Gyawali R (2015) Antimicrobial activity and phytochemical screening of some traditionally used Nepalese medicinal plants. Int J Pharm Biol Arch 6:20-25

14. Daji G, Steenkamp P, Madala N, Dlamini B (2018) Phytochemical composition of Solanum retroflexum with the aid of ultra-performance liquid chromatography hyphenated to quadrupole time of flight mass spectroscopy (UPLC-qTOF-MS). J Food Qual 2018:1-8

15. Iqbal M, Tao Y, Xie S, Zhu Y, Chen D, Wang X, Huang L, Peng D, Sattar A, Shabbir MAB, Hussain HI, Ahmed S, Yuan Z (2016) Aqueous two-phase 
system (ATPS): an overview and advances in its applications. Biol Proced Online 18:1-18

16. Xavier L, Freire M, Vidal-Tato I, Ivarez I (2014) Aqueous two phase systems for the extraction of phenolic compounds from euclyptus (Eucalyptus globulus) wood industrial wastes. J Chem Technol Biotechnol 89:1772-1778

17. Chethana S, Navak C, Madhusudhan M, Raghavaraq K (2015) Single step aqueous two-phase extraction for downstream processing of C-phycoccyanin from Spirulina platensis. J Food Sci Technol 52:2415-2421

18. Iqbal M, Tao Y, Xie S, Zhu Y, Chen D, Wang X, Huang L, Peng D, Sattar A, Shabbir MAB, Hussain HF, Ahmed S, Yuan Z (2016) Aqueous two phase system (ATPS):an overview and advances in its applications. Biol Proced Online 18:1-18

19. Saraswat M, Musante L, Ravida A, Shortt B, Byne B, Holthofer H (2013) Preparative purification of recombinant proteins: current status and future trends. BioMed Res Int 2013:1-18

20. Zhang J, Wu H, Kim E, El-Shourbagy TA (2009) Salting-out assisted liquid/ liquid extraction with acetonitrile: a new high throughput sample preparation technique for good laboratory practice bioanalysis using liquid chromatography-mass spectrometry. Biomed Chromatogr 23:419-425

21. Hernández-Mesa M, Cruces-Blanco C, García-Campaña AM (2018) Simple and rapid determination of 5-nitroimidazoles and metabolites in fish roe samples by salting-out assisted liquid-liquid extraction and UHPLC-MS/ MS. Food Chem 252:294-302

22. Mottier L, Alvarez L, Ceballos L, Lanusse C (2006) Drug transport mechanisms in helminth parasites: passive diffusion of benzimidazole anthelmintics. Exp Parasitol 113:49-57

23. Mitrowska K, Posyniak A, Zmudzki J (2010) Multiresidue method for the determination of nitroimidazoles and their hydroxy-metabolites in poultry muscle, plasma and egg by isotope dilution liquid chromatography-mass spectrometr. Talanta. 81:1273-1280

24. Granja RHMM, Nino AMM, Reche KVG, Giannotti FM, Lima AC, Wanschel ACBA, Salerno AG (2013) Determination and confirmation of metronidazole, dimetridazole, ronidazole and their metabolites in bovine muscle by LC-MS/MS. Food Addit Contam Part A 30:970-976

25. Tejada-Casado C, Olmo-Iruela M, Garcia-Campiana AM, Lara FG (2018) Green and simple analytical method to determine benzimidazoles in milk samples by using salting-out assisted liquid-liquid extraction and capillary liquid chromatography. J Chromatogr B 1091:46-52

26. Sazali NH, Alshishani A, Saad B, Chew KY, Chong MM, Miskam M (2019) Salting out assisted liquid liquid extraction coupled with high performance liquid chromatography for the determination of vitamin D3 in milk samples. R Soc Open Sci 6:1-8

27. Ramabulana T, Mavunda RD, Steenkamp PA, Piater LA, Dubery IA, Madala NE (2015) Secondary metabolite perturbations in Phaseolus vulgaris leaves due to gamma radiation. Plant Physiol Biochem 95:287-295

28. Madala NE, Tugizimana F, Steenkamp PA (2014) Development and optimization of an UPLC-QTOF-MS/MS method based on an in-source collision induced dissociation approach for comprehensive discrimination of chlorogenic acids isomers from Momordica plant species. J Anal Methods Chem 2014:1-7

29. Deshpande S, Jaiswal R, Matei MF, Kuhnert N (2014) Investigation of acyl migration in mono - and dicaffeoylquinic acids under aqueous basic, aqueous acidic, and dry roasting conditions. J Agr Food Chem 62:9160-9170

30. Mhlongo ML, Piater LA, Steenkamp PA, Madala NE, Dubery IA (2014) Priming agents of plant defence stimulate the accumulation of mono and di-acylated quinic acids in cultured tobacco cells. Physiol Mol Biol Pla 88:61-66

31. Khoza BS, Gbashi S, Steenkamp PA, Njobeh PB, Madala NE (2016) Identification of hydroxylcinnamoyl tartaric acid esters in Bidens pilosa by UPLC-tandem mass spectrometry. S Afr J Bot 103:95-100

32. Pinela J, Montoya C, Carvalho AM, Martins V, Rocha F, Barata AM, Barros L, Ferreira CFRI (2019) Phenolic composition and antioxidant properties of ex-situ conserved tomato (Solanum lycopersicum L.) germplasm. Food Res 125:1-9

33. Tata A, Perez CJ, Hamid TS, Bayfield MA, Ifa DR (2015) Analysis of metabolic changes in plant pathosystems by imprint imaging DESI-MS. J Am Soc Mass Spectrom 26:641-648

34. Mweetwa AM (2009) Biosynthesis of steroidal glycoalkaloids in solanum chacoense bitter, Dissertation submitted to the faculty of Virginia
Polytechnic Institute and State University in partial fulfillment of the requirements for the degree of Doctor of Philosophy in Horticulture

35. Abu-Reidah IM, Ali-Shtayeh MS, Jamous RM (2015) Comprehensive metabolite profiling of arum Palestinian (Aracaea) leaves by using liquid chromatography tandem mass spectrometry. Food Res 70:74-86

36. Che Y, Wang Z, Zhu Z, Ma Y, Zhang Y, Gu W, Zhang J, Rao G (2016) Simultaneous qualitation and quantitation of chlorogenic acids in kuding tea using ultra-high-performance liquid chromatography-diode array detection coupled with linear ion trap-orbitrap mass spectrometer. Molecules 12:1-14

37. Upadhyay R, Rao LJM (2013) An outlook on chlorogenic acids occurrence, chemistry, technology and biological activities. Crit Rev Food Sci Nutr 53:968-984

38. Liang N, Kitts DD (2015) Role of chlorogenic acids in controlling oxidative and inflammatory stress conditions. Nutrients 8:1-20

39. Park JB (2019) Concurrent HPLC detection of javamide-1/-11, caffeine, 3-O-caffeoylquinic acid, 4-O-caffeoylquinic acid and 5-O-caffeoylquinic acid; their comparative quantification and instant coffees. Sep Sci Plus 2:230-236

40. Hernández L, Carranza P, Cobos LE, López LI, Ascasio JA, Silva SY (2017) Bioguided fractionation from Solanum elaeagnifolium to evaluate toxicity on cellular lines and breast tumor explants. Vitae 24:124-131

41. Filho EG, Silva LMA, Brito ES, Wurlitzer NJ, Fernandes FA, Rabelo MC, Rodrigues TV (2018) Evaulation of thermal and non-thermal processing effect on non-prebiotic and prebiotic acerola juices using 1 H NMR and GC-MS coupled to chemometrics. Food Chem 265:23-31

42. Martucci MEP, Vos RCH, Carollo CA, Gobbo-Neto L (2014) Metabolomics as a potential chemotaxonomical tool: application in the genus Vernonia Schreb. PLOS ONE 9:1-8

43. Harborne JB, Baxter H (1999) The Handbook of Natural Flavonoids, 1, 181. Flavonols, University of Reading, Whiteknights, Reading RG6 6AS (United Kingdom)

44. Rastrelli L, Saturnino P, Schettino O, Dini A (1995) Studies on the constituents of Chenopodium pallidacaule (Canihua) seeds. isolation and characterization of two flavanol glycosides. J Agr Food Chem 43:2020-2024

45. Litvinov VP (2007) Chemistry and biological activities of 1, 8 naphthyridines. Russ Chem Rev 73:637-670

46. Sharma DK (2006) Pharmacological properties of flavonoids including flavonolignans-integration of petrocrops with drug development from plants. J Sci Ind Res 65:477-484

47. Govindaraju K, Tamilselvan S, Kiruthiga V (2019) Biogenic silver nanoparticles by Solanum torvum and their promising antimicrobial activity. J Biopest 3:394-399

48. Makitan C, Chimuka L, Steenkamp P, Cukrowska E (2016) Comparative analyses of flavonoid content in Moringa oleifera and Moringa ovalifolia with the aid of UHPLC-qTOF-MS fingerprinting. S Afr J Bot 105:1 16-122

49. Dewey RE, Xie J (2013) Molecular genetics of alkaloid biosynthesis in Nicotiana tabacum. Phytochemistry 94:10-27

50. Chen Y, Li S, Sun F, Han H, Zhang X, Fan Y, Tai G, Zhou Y (2010) In-vivo antimalarial activities of glycoalkaloids isolated from Solanaceae plants. Pharm Biol 48:1018-1024

51. Al Sanani SS, Eltayeb EA, Kamal YT, Khan MS, Ahmad S (2016) Variations in the cytotoxic glycoalkaloids solamargine and solasonine in different parts of the Solanum incanum plant during its growth and development in Oman. J Talibah Univ Sci 10:813-822

52. Ruprich J, Rehurkova I, Boon PE, Busk L, Bosgra S, Rehurkova I, Hart A, Klaveren J, Marvin H, Van der Voet H (2009) Probabilistic modelling of exposure doses and implications for health risk characterization: Glycoalkaloids from potatoes. Food Chem Toxicol 47:2899-2905

53. Hawas UW, Soliman GM, El-Kassim LFA, Farrang AR, Mahmoud K, Leon F (2013) A new flavonoid C-glycoside from Solanum elaegnifolium with hepatoprotective and curative activities against paracetamol induced liver injury in mice. Z Naturforschung C 68:19-28

54. Jia B, Xu L, Guan W, Lin Q, Brennan C, Yan R, Zhao H (2019) Effect of citronella essential oil fumigation on sprout suppression and quality of potato tubers during storage. Food Chem 2019:254-258

55. Maxwell A, Pingal R, Reynolds WF, McLean S (1996) Aminospirosolane alkaloids from Solanum arboretum. Phytochemistry 43:913-915

56. Neves CMMS, Cássia SSR, Pereira MM, Freire MG, Coutinho JAP (2019) Understanding the effect of ionic liquids as adjuvants in partition of 
biomolecules in aqeous two-phase systems formed by polymers and weak salting-out agents. Biochem Eng J 141:239-246

57. Russo D (2008) The impact of kosmotropes and chaotropes on bulk and hydration shell water dynamics in a model peptide solution. Chem Phys 345:200-211

58. Olga YK, Ilya NK, Ilya IK, Vladimir IL (2018) Cryostructuring of polymeric systems, influence of organic chaotropes and kosmotropes on the cryotropic gel-formation of aqueous poly(vinyl alcohol) solutions. Eur Polym J 102:169-177

59. Assaf Kl, Nau WM (2018) The chaotropic effect as an assembly motif in chemistry. Angew Chem 57:13968-13981

60. Roy JC, Das S, Islam N (2019) Influence of kosmotropes and chaotropes on the kraft temperature and critical micelle concentration of tetradecyltrimethylammonium bromide in aqueous solution. J Solution Chem 48:758-773

61. Qian H, Peng X, Han X, Ren J, Sun L, Fu Z (2013) Comparison of the toxicity of silver nanoparticles and silver ions on the growth of terrestrial plant model Arabidopsis thaliana. J Environ Sci Int 25:1947-1956

62. Amooaghaie R, Tabatabaei F, Ahadi AM (2015) Role of hematin and sodium nitroprusside in regulating Brassica nigra seed germination under nanosilver and silver nitrate stresses. Ecotoxicol Environ 113:259-270

63. Gubbins EJ, Batty LC, Lead JR (2011) Phytotoxicity of silver nanoparticles to Lemna minor L. Environ Pollut 159:1551-1559
64. Lee WM, Kwak JI, An YJ (2012) Effect of silver nanoparticles in crop plants Phaseolus radiatus and sorghum bicolor: media effect on phytotoxicity. Chemosphere 86:491-499

65. Al-Huqail AA, Hatata MM, Ibrahim MM (2018) Preparation, characterization of silver phytonanoparticles and their impact on growth potential of Lupinus termis L. seedlings. Saudi J Biol Sci 25:313-319

66. Nainegali BS, lyyaswami R, Belur PD (2019) Simultaneous extraction of four different bioactive compounds from Garcinia indinca and their enrichment using aqeous two phase systems. Food Bioprod Process 114:185-195

67. Zhang ZF, Wang R, Ye F, Wang H, Zhao W (2019) Extraction of glycyrrhizic acid by aqueous two-phase system formed by PEG and two environmentally friendly organic acid salts - sodium citrate and sodium tartrate. Green Process Synth 8:551-556

68. Santos RP, Souza LM, Balieiro AL, Soares CMF, Lima AS, Souza RL (2017) Integrated process of extraction and purification of betanin from Opuntia ficus-indica using aqueous two-phase systems based on THF and sodium salts. Sep Sci Technol 53:734-744

\section{Publisher's Note}

Springer Nature remains neutral with regard to jurisdictional claims in published maps and institutional affiliations.

\section{Submit your manuscript to a SpringerOpen ${ }^{\circ}$ journal and benefit from:}

- Convenient online submission

- Rigorous peer review

- Open access: articles freely available online

- High visibility within the field

- Retaining the copyright to your article

Submit your next manuscript at $\boldsymbol{\nabla}$ springeropen.com 